\title{
Addressing the Gag Reflex: A Literature Review
}

\author{
${ }^{1}$ Sweta K Pisulkar, ${ }^{2}$ Ruchi Agrawal, ${ }^{3}$ Surekha R Godbole, ${ }^{4}$ Vivek Jadhav
}

\begin{abstract}
Gagging is an involuntary protective reflex. Some patients have an extremely low threshold for the gag reflex. A severe gag reflex can be a big obstacle in certain dental procedures especially during the making of a maxillary impression. Many dental patients avoid going to the dentist because of an abnormally severe gag reflex. Treating such group of patients can be stressful and a time-consuming experience, both for the dentist and for the patient. The main aim of this article is to understand the etiology and effective management of such patients for a stress-free and fruitful clinical practice.
\end{abstract}

Keywords: Gagging, Management, Neurophysiology of gagging, Severity index.

How to cite this article: Pisulkar SK, Agrawal R, Godbole SR, Jadhav V. Addressing the Gag Reflex: A Literature Review. Int J Recent Surg Med Sci 2018;4(1):2-4.

Source of support: Nil

Conflict of interest: None

\section{INTRODUCTION}

Making a maxillary impression can be the worst 45 seconds of life for both the patient and the dentist due to gagging. A severe gag reflex can be a big obstacle in certain procedures, as it prevents the patients from seeking regular oral health care services comfortably. Gagging is a normal, physiological, defense reflex mechanism that prevents entry of foreign bodies into the trachea, pharynx, or larynx. ${ }^{1}$ If foreign body enters the trachea, pharynx, or larynx, then involuntary contraction of the muscles of soft palate or the pharynx results, which leads to retching.

In retching, peristalsis becomes uncoordinated, spasmodic, and reversed in direction. As air is forced over the closed glottis, characteristic retching sound is

\footnotetext{
${ }^{1,4}$ Associate Professor, ${ }^{2}$ Resident, ${ }^{3}$ Professor and Head

1-3 Department of Prosthodontics, Sharad Pawar Dental College Datta Meghe Institute of Medical Sciences University, Wardha Maharashtra, India

${ }^{4}$ Department of Prosthodontics, Chhatrapati Shahu Maharaj Shikshan Sanstha, Aurangabad, Maharashtra, India
}

Corresponding Author: Sweta K Pisulkar, Associate Professor Department of Prosthodontics, Sharad Pawar Dental College Datta Meghe Institute of Medical Sciences University, Wardha Maharashtra, India, e-mail: drsweta15@gmail.com produced. This reflex is perfectly a natural part of our body's self-defense mechanism, as it prevents something from entering the throat that prevents choking except as part of normal swallowing. ${ }^{2}$

\section{ETIOLOGY}

The etiology of hyperactive gagging is listed in Table $1 .^{3}$

\section{NEUROPHYSIOLOGY OF GAGGING}

The origin of gagging can be somatic or psychogenic. Somatic gagging is initiated by sensory nerve stimulation from direct contact of trigger area. Although trigger areas are specific to individuals, sites, such as certain parts of the palate and the lateral borders of the tongue commonly elicit the gag reflex. Psychogenic gagging controlled by higher centers of the brain is induced without direct contact. The sound, smell, sight, or even the thought of dental treatment can be enough to initiate the gag reflex in some individuals. These receptors are located on the posterior third of the tongue or the soft palate, and are subsequently conveyed by the sensory neuron via afferent (toward the brain) nerves to the gag center located in the medulla oblongata (lower portion of the brain). Then, from this center, motor neurons via efferent (away from the brain) nerve fibers are conveyed to the throat muscles that are involved in gagging (Fig. 1). ${ }^{2}$

\section{ASSESSMENT OF GAGGING}

Dickinson and Fiske gagging severity index is listed in Table ${ }^{1}{ }^{1}$

\section{MANAGEMENT TECHNIQUES}

- Behavior modification

- Desensitization

- Conditioning prosthesis

- Pharmacological methods

- Acupuncture and acupressure

- Miscellaneous methods:

- Reduction of palatal coverage of maxillary denture

- Hypnosis

- Friedman's method

\section{Behavioral Modification}

Relaxation can help ameliorate the memory of treatments performed. An example of this is by asking the patient to relax and tense certain muscle, starting from legs and 
Addressing the Gag Reflex

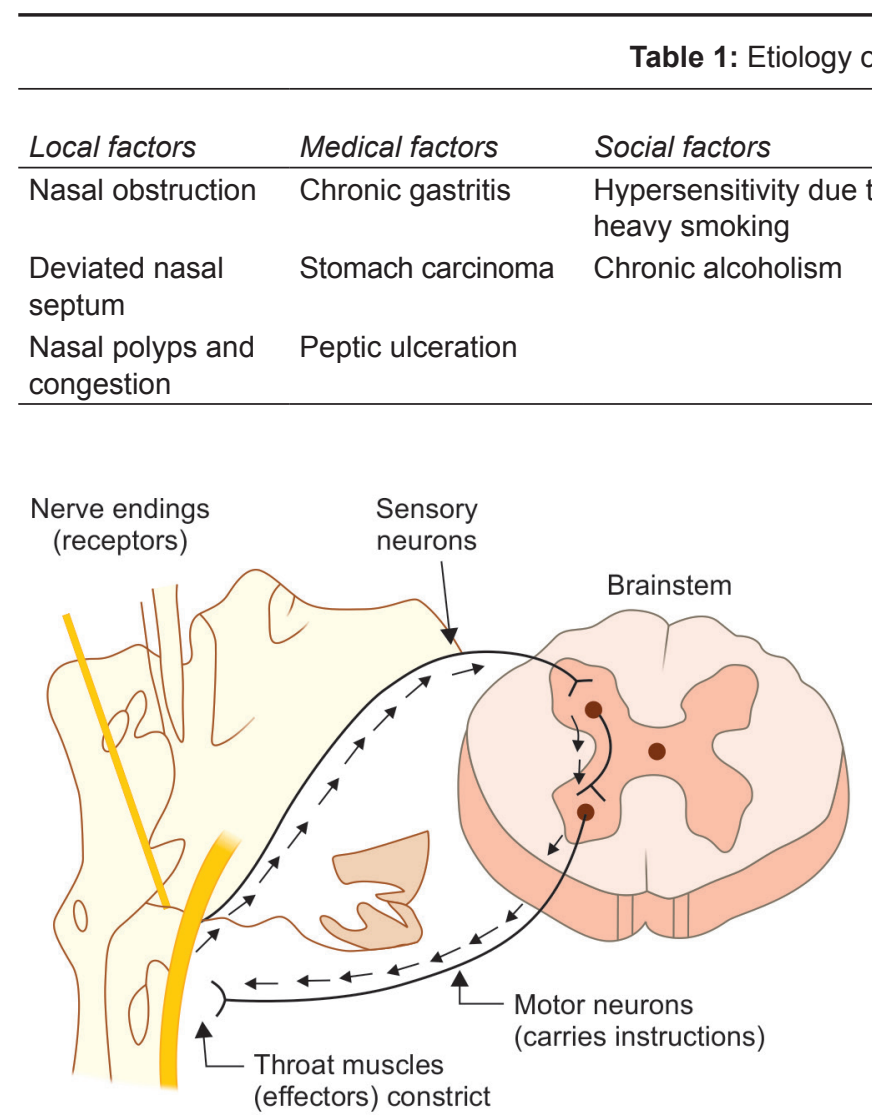

Fig. 1: Neurophysiology of gagging

working upward, while reassuring the patient continuously in a calm atmosphere. ${ }^{2}$

\section{Distraction}

Interaction with the patient can be useful, or instruct the patient to concentrate on breathing, i.e., inhaling through nose and exhaling through mouth.

The process of "distraction imagery" should be practiced in which the clinician verbally explains the process being performed with a feeling of well-being. ${ }^{2}$

\section{Desensitization}

This technique consists of exposing the patient to the feared stimulus in a way that the frequency, intensity, and duration of the noxious stimulus are slowly increased, thereby making the patient to slowly habituate to the procedure to be performed. $^{2}$

Singer's Marble technique ${ }^{4}$ is an effective way of desensitization for treating hopeless gaggers. In this technique, no oral examination of any kind was made at the first office visit. The patient was told to put five glass, round, multicolored marbles, 0.5 inch in diameter approximately, one by one, until all the five marbles were in his mouth.

The patient was assured that if he swallowed a marble, it could not harm him as the fear of swallowing a foreign
Table 2: Dickinson and Fiske gagging severity index

\begin{tabular}{ll}
\hline Grade & Severity \\
\hline I & $\begin{array}{l}\text { Normal gagging; very mild, occasional, and controlled } \\
\text { by the patient }\end{array}$ \\
II & $\begin{array}{l}\text { Mild gagging; control is acquired by the patient with } \\
\text { reassurance from the dental team }\end{array}$ \\
III $\quad \begin{array}{l}\text { Moderate gagging; consistent and limits treatment } \\
\text { options }\end{array}$ \\
IV $\quad \begin{array}{l}\text { Severe gagging; occurs with all forms of treatment, } \\
\text { including simple visual examination }\end{array}$ \\
V $\quad \begin{array}{l}\text { Very severe gagging; affecting patient behavior and } \\
\text { dental attendance and making treatment impossible }\end{array}$ \\
\hline
\end{tabular}

object could induce the gagging. Simultaneously, during each weekly visit, continual assurance that he would be able to wear dentures was given to the patient. The patient was urged to continuously keep the five marbles in his mouth for 1 week, except when eating and sleeping. In the second visit, the patient was able to tolerate the five marbles and was reassured that he would be able to wear dentures, which further fortifies motivation. In the third and fourth visits, the hard palate, the soft palate, the cheeks, the lips, and the tongue were swabbed with topical anesthetics before impression making was attempted. The patient was advised to keep three marbles in his mouth.

\section{Conditioning Prosthesis}

A conditioning denture controls gagging very effectively. The conditioning prosthesis is similar to an orthodontic appliance (Hawley's) that consists of palatal alveolar prosthesis fabricated in acrylic resin. This appliance must be worn continuously for 1 week followed by an interval of 1 week for absolute adaptation. ${ }^{5-7}$

\section{Pharmacological Treatment}

- Local anesthetics: The application of local anesthetics has shown to reduce gag reflex. A variety of agents to be applied are available in the form of gels, lozenges, mouth rinses, sprays, or injection. Topical lidocaine can be applied with a cotton roll on palate and back of the tongue. ${ }^{8}$

- Conscious sedation: The sedation medications help the patient achieve a total state of relaxation. It enables 
clinician to work comfortably and the patient has little memory of the appointment. ${ }^{9}$

- General anesthesia: Though general anesthesia is not much advised on a regular basis, it can be considered in patients who do not respond to any form of sedation or behavioral therapy.

\section{Acupuncture and Acupressure}

Acupuncture of point pericardium 6 located on the forearm and conception vessel 24 located on the chin can moderate the gag reflex in the majority of patients who are unable to accept an upper alginate impression, and sufficiently well to allow dental treatment to be carried out. This technique is quick, safe, inexpensive, relatively noninvasive, and little additional time is required., ${ }^{1,10}$

\section{Miscellaneous Methods}

- Reduction of palatal coverage of maxillary denture. The size of maxillary denture can be decreased to a U-shaped border situated $10 \mathrm{~mm}$ from the dental arch approximately. The reduction in the size of the denture influences their sense of taste positively, and gagging is reduced surprisingly. ${ }^{7}$

- Hypnosis provides the clinician with a set of techniques, which may be used to augment or facilitate a particular course of treatment. The success of this technique is dependent highly upon the strength of the operator's conviction. ${ }^{2,11}$

- Friedman's technique: Friedman reported that with some gagging patients, common table salt can minimize the reflex. Salt may help gagging patients tolerate complete dentures when placed in liberal amounts on the palatal region of the denture or on the tongue. ${ }^{12}$

\section{SUMMARY}

A strong potential for compromised treatment is the most serious consequence associated in patients with hyperactive gag reflex. A complete oral examination, medical history, and conversation with the patient are important sources of information that assist with the management of gagging problems. Exaggerated gag reflex can be controlled by numerous available techniques and the same technique may not solve every patient's problem. The cause or causes involved should dictate the technique or techniques used.

\section{REFERENCES}

1. Rosted P, Bundgaard M, Fiske J, Pedersen AM. The use of acupuncture in controlling the gag reflex in patients requiring an upper alginate impression: an audit. Br Dent J 2006 Dec;201(11):721-725.

2. Shrivastav VK, Mahajan S. Effective management of gag reflex in clinical practice. Indian J Stomatol 2012 Jan;3(1):27-31.

3. Ahmad N, Yunus N, Jafri Z. Etiology and management of gag reflex in the prosthodontic clinic: a review. Int J Oral Health Dent 2015 Jan-Mar;1(1):25-28.

4. Singer IL. The marble technique: a method for treating the "hopeless gagger" for complete dentures. J Prosthet Dent 1973 Feb;29(21):146-150.

5. Savage RD, MacGregor RR. Behaviour therapy in prosthodontics. J Prosthet Dent 1970 Aug;24(2):126-132.

6. Jordan LJ. Are prominent rugae and glossy tongue surfaces desired on artificial dentures? J Prosthet Dent 1954;4:52-53.

7. Borkin DW. Impression technique for patients that gag. J Prosthet Dent 1959 May-Jun;9(3):386-387.

8. Braham RB, Braham RL. The management of the chronic or pharynx and palate. ASDC J Dent Child 1977 Mar-Apr; 44(2):111-116.

9. Yagiela JA. Making patients safe and comfortable for a lifetime of dentistry: frontiers in office-based sedation. J Dent Educ 2001 Dec;65(12):1348-1356.

10. Vachiramon A, Wang WC. Acupressure technique to control gag reflex during maxillary impression procedures. J Prosthet Dent 2002 Aug;88(2):236.

11. Barsby MJ. The use of hypnosis in the management "gagging" and intolerance to dentures. Br Dent J 1994 Feb;176(3):97-102.

12. Friedman MH, Weintraub MI. Temporary elimination of gag reflex for dental procedures. J Prosthet Dent 1995 Mar;73(3):319. 